\title{
The continuous strength method for the design of circular hollow sections
}

\author{
Craig Buchanan ${ }^{\mathrm{a}, *}$, Leroy Gardner ${ }^{\mathrm{a}}$, Andrew Liew $^{\mathrm{b}}$ \\ ${ }^{a}$ Department of Civil and Environmental Engineering, Imperial College London, London, \\ $U K$ \\ ${ }^{b}$ Department of Civil, Environmental and Geomatic Engineering, Swiss Federal Institute of \\ Technology (ETH), Zurich, Switzerland
}

\begin{abstract}
Circular hollow sections (CHS) are widely used in a range of structural engineering applications. Their design is covered by all major design codes, which currently use elastic, perfectly-plastic material models and cross-section classification to determine cross-section compressive and flexural resistances. Experimental data for stocky sections show that this can result in overly conservative estimates of cross-section capacity. The continuous strength method (CSM) has been developed to reflect better the observed behaviour of structural sections of different metallic materials. The method is deformation based and allows for the rational exploitation of strain hardening. In this paper, the CSM is extended to cover the design of non-slender and slender structural steel, stainless steel and aluminium CHS, underpinned by and validated against 342 stub column and bending test results. Comparisons with the test results show that, overall, the CSM on average offers more accurate and less scattered predictions of axial and flexural capacities than existing design methods.
\end{abstract}

Keywords: circular hollow sections, continuous strength method, cross-section classification, local buckling, strain hardening

\footnotetext{
${ }^{*}$ Corresponding author

Email address: craig.buchanan08@imperial.ac.uk (Craig Buchanan)
} 


\section{Introduction}

Circular hollow sections (CHS) have been manufactured and used in structures since the early 1800s as columns, beams, tension members and truss elements [1. They have become increasingly attractive to designers due to their aesthetic 5 appearance and their benefits over open sections such as superior torsional resistance, bi-axial bending resistance, reduced drag and loading in a fluid, ability to be filled with concrete to form a composite section and their reduced maintenance requirements with a smaller external area exposed to corrosive environments [1]. CHS are primarily thin-walled structural elements, and therefore local buckling, whether prior or subsequent to material yielding, is a primary consideration in their design.

\subsection{Traditional CHS design methods}

Current design codes use the concept of cross-section classification to separate circular hollow sections into discrete classes depending upon their susceptibility to local buckling. Four classes of cross-section are considered in EN 1993-1-1 [2] and BS 5950-1 [3] for structural steelwork, EN 1993-1-4 [4] for stainless steel and EN 1999-1-1 [5] for aluminium. In bending, class 1 cross-sections can reach and maintain their full plastic moment capacity $M_{p l}$ with suitable rotation capacity for plastic design. Class 2 cross-sections are also capable of reaching their full 20 plastic moment capacity but with limited rotation capacity. There is no equivalent to class 2 cross-sections in the AISC 360 [6] and AS 4100 [7] structural steel codes. Class 3 cross-sections are unable to reach their plastic moment capacity due to local buckling and their bending capacity is limited to the elastic moment capacity $M_{e l}$. Class 4 cross-sections experience local buckling before reaching their elastic moment capacity, and are typically referred to as slender. In terms of axial resistance, the class 3 limit separates the non-slender cross-sections that are fully effective in compression (i.e. classes 1-3) from those that fail by local buckling before reaching their yield load (i.e. class 4). These traditional design methods also limit the maximum stress in the cross-section to the yield strength 
$f_{y}$, neglecting the beneficial effects of strain hardening in metallic materials. Experimental results have shown that cross-section classification and limiting the maximum stress to the yield stress can be overly conservative in estimating the resistance of stocky (class 1-3, non-slender) cross-sections [8]. It is therefore apparent that there are structural efficiency improvements to be sought over 35 existing design methods for CHS.

\subsection{The continuous strength method}

The continuous strength method (CSM) has been developed in recent years to reflect better the observed characteristics of metallic structural elements.

40 Cross-section classification is replaced with a continuous relationship between cross-section slenderness and deformation capacity (referred to in Section 2.5 as the base curve), reflecting the continuous nature of cross-section capacity varying with local slenderness. A strain hardening material model is also adopted, representing the behaviour seen in material tests, with an increase in strength 45 above the yield strength under plastic deformation.

The CSM has previously been developed for structural steel [8 10, stainless steel [1] and aluminium 12 plated cross-sections, such as I-sections, square hollow sections (SHS) and rectangular hollow sections (RHS) in compression and bending, and also under combined bending [13. The previous work has shown that the CSM predicts enhanced capacities over existing methods; for example, in the case of stainless steel, average enhancements in compressive and bending resistances of $12 \%$ and $19 \%$ respectively were found [11]. The natural progression is to extend the application of the CSM to circular hollow sections, which is the focus of the present paper that builds upon prior work [14, and the development process is described herein. 


\section{Extension of the CSM to CHS design}

The process of extending the CSM to cover the design of CHS requires: i) the identification of the yield slenderness limit (i.e. the local slenderness limit below which significant benefit from strain hardening can be derived for non-slender cross-sections); ii) the formulation of the CSM non-slender and slender base curves defining the relationship between cross-section slenderness and deformation capacity; iii) the selection of appropriate material models; and iv) the derivation of resistance functions.

The local cross-section slenderness $\bar{\lambda}_{c}$ is defined in non-dimensional form by Eq. 1.

$$
\bar{\lambda}_{c}=\sqrt{\frac{f_{y}}{\sigma_{c r}}}
$$

where $f_{y}$ is the material yield strength and $\sigma_{c r}$ is the elastic critical buckling stress, which for a CHS in compression is calculated using Eq. 2 .

$$
\sigma_{c r}=\frac{E}{\sqrt{3\left(1-\nu^{2}\right)}} \frac{2 t}{D}
$$

where $E$ is the Young's modulus, $\nu$ is the Poisson's ratio, $D$ is the outer diameter and $t$ is the wall thickness of the CHS.

Timeshenko [15] suggested that the local buckling stress in bending can be taken as 1.4 times that in compression based on experimental results [16], which effectively makes a cross-section in bending more stocky than the same crosssection in compression. Gerard and Becker [17] proposed a factor of 1.3 based upon the findings of Flügge [18]. However more recent analytical work [19 21] has showed that the maximum critical stress in bending is equal to the critical compressive stress for practical cylinder lengths. Differences also exist between international design codes in their treatment of compression and bending for CHS. Gardner et al. 22] noted that EN 1993-1-1 [2] and EN 1999-1-1 [5] utilise the same class 3 limits for both compression and bending, in contrast to BS 
5950-1 [3], EN 1993-1-4 [4], AISC 360 [6] and AS 4100 [7] where different limits are used. Utilising different slenderness limits in compression and bending is equivalent to applying a factor to the local buckling stress. Given the findings of the more recent research [19 21] and the conservative nature of the choice, the elastic critical buckling stress in bending will be taken to be the same as that in compression (see Eq. 2 ) in the present study and within the CSM.

\subsection{CHS experimental database}

A dataset of 342 experimental results on CHS in compression or bending has been collated from the literature. The dataset includes stub column test results for hot-finished structural steel [23 27, very high strength structural steel 28, 29, cold-formed structural steel [25, 26, 28, 30,47, austenitic stainless steel [48 57, duplex stainless steel [51, 58, 59, ferritic stainless steel [60 and aluminium [61, 62], and four-point bending test results for hot-finished structural steel [63 66], very high strength structural steel [67, cold-formed structural steel [34, 63, 66, 68, 73, austenitic stainless steel [4, 74, 75], duplex stainless steel [74] and aluminium [76, 77]. Note that the very high strength structural steel had a typical yield stress $f_{y}$ around $1300 \mathrm{MPa}$ 29. The number of experimental results used in the definition and assessment of the various aspects of the CSM for CHS, i) the yield slenderness limit (see Section 2.3); ii) the base curve for non-slender sections (see Section 2.5p; iii) the base curve for slender sections (see Section 2.5); and iv) the assessment of the capacity predictions (see Section 4) are shown in Tables 1 and 2 for compression and bending respectively. The number of specimens used in the different stages of the extension of the CSM to CHS sometimes varies since not all required parameters were reported in the literature.

\subsection{Yield slenderness limit}

The limiting local slenderness that delineates the transition between slender and non-slender cross-sections needs to be defined. Above this limit there is no 


\begin{tabular}{|c|c|c|c|c|c|}
\hline \multirow[t]{2}{*}{ Material } & \multirow{2}{*}{$\begin{array}{l}\text { Yield slen- } \\
\text { derness } \\
\text { limit } \\
\text { - }\end{array}$} & \multirow{2}{*}{$\begin{array}{l}\text { Base curve } \\
\text { Non- } \\
\text { slender } \\
\text { sections }\end{array}$} & \multirow[b]{2}{*}{$\begin{array}{l}\text { Slender } \\
\text { sections }\end{array}$} & \multicolumn{2}{|c|}{$\begin{array}{l}\text { CSM and code ca- } \\
\text { pacity predictions }\end{array}$} \\
\hline & & & & $\begin{array}{l}\text { Non- } \\
\text { slender } \\
\text { sections }\end{array}$ & $\begin{array}{l}\text { Slender } \\
\text { sections }\end{array}$ \\
\hline $\begin{array}{l}\text { Hot-finished struc- } \\
\text { tural steel }\end{array}$ & 11 & 8 & - & 9 & - \\
\hline $\begin{array}{l}\text { Very high strength } \\
\text { structural steel }\end{array}$ & 20 & 1 & 14 & 1 & 19 \\
\hline $\begin{array}{l}\text { Cold-formed struc- } \\
\text { tural steel }\end{array}$ & 131 & 48 & 50 & 44 & 52 \\
\hline $\begin{array}{l}\text { Stainless steel (to- } \\
\text { tal) }\end{array}$ & 76 & 31 & 26 & 39 & 35 \\
\hline $\begin{array}{l}\text { Austenitic stainless } \\
\text { steel }\end{array}$ & 48 & 16 & 13 & 24 & 22 \\
\hline $\begin{array}{l}\text { Duplex stainless } \\
\text { steel }\end{array}$ & 21 & 10 & 11 & 10 & 11 \\
\hline $\begin{array}{l}\text { Ferritic stainless } \\
\text { steel }\end{array}$ & 7 & 5 & 2 & 5 & 2 \\
\hline Aluminium & 15 & 7 & 7 & 7 & 8 \\
\hline
\end{tabular}

Table 1: Number of CHS stub column test results used in the development of the various aspects of the CSM. 


\begin{tabular}{|c|c|c|c|c|c|}
\hline \multirow[t]{2}{*}{ Material } & \multirow{2}{*}{$\begin{array}{l}\text { Yield slen- } \\
\text { derness } \\
\text { limit } \\
\text { - }\end{array}$} & \multirow{2}{*}{$\begin{array}{l}\text { Base curve } \\
\text { Non- } \\
\text { slender } \\
\text { sections }\end{array}$} & \multirow[b]{2}{*}{$\begin{array}{l}\text { Slender } \\
\text { sections }\end{array}$} & \multicolumn{2}{|c|}{$\begin{array}{l}\text { CSM and code ca- } \\
\text { pacity predictions }\end{array}$} \\
\hline & & & & $\begin{array}{l}\text { Non- } \\
\text { slender } \\
\text { sections }\end{array}$ & $\begin{array}{l}\text { Slender } \\
\text { sections }\end{array}$ \\
\hline $\begin{array}{l}\text { Hot-finished struc- } \\
\text { tural steel }\end{array}$ & 14 & 2 & - & 14 & - \\
\hline $\begin{array}{l}\text { Very high strength } \\
\text { structural steel }\end{array}$ & 12 & 1 & 8 & 1 & 11 \\
\hline $\begin{array}{l}\text { Cold-formed struc- } \\
\text { tural steel }\end{array}$ & 44 & 9 & 17 & 13 & 27 \\
\hline $\begin{array}{l}\text { Stainless steel (to- } \\
\text { tal) }\end{array}$ & 12 & 1 & 8 & 3 & 9 \\
\hline $\begin{array}{l}\text { Austenitic stainless } \\
\text { steel }\end{array}$ & 8 & 1 & 4 & 3 & 5 \\
\hline $\begin{array}{l}\text { Duplex stainless } \\
\text { steel }\end{array}$ & 4 & - & 4 & - & 4 \\
\hline $\begin{array}{l}\text { Ferritic stainless } \\
\text { steel }\end{array}$ & - & - & - & - & - \\
\hline Aluminium & 7 & 3 & 4 & 3 & 4 \\
\hline
\end{tabular}

Table 2: Number of CHS four-point bending test results used in the development of the various aspects of the CSM. 
significant benefit from strain hardening with the cross-section buckling locally below the yield load in compression or elastic moment in bending. This limit is identified by plotting the ultimate capacity of the stub columns normalised by their yield load $\left(N_{u} / N_{y}\right)$ against cross-section slenderness $\bar{\lambda}_{c}$, defined by Eq. 1 . as shown in Fig. 1. A linear regression fit can then identify the limiting local slenderness where the ultimate axial load equals the yield load, which from Fig. 1. is $\bar{\lambda}_{c} \approx 0.40$. The class 3 limits from current design codes are also plotted in Fig. 1 , and it can be seen that the identified limiting local slenderness is compatible with the class 3 limit for aluminium given in EN 1999-1-1 [5]; however it is above the existing structural steel and stainless steel class 3 limits. There is also some scatter in the stub column dataset. Consequently, a lower value of $\bar{\lambda}_{c}=0.3$ for the yield slenderness limit is proposed as this represents approximately a lower bound to the assembled dataset and is generally comparable with existing codes.

It is evident from Fig. 1 that there are no clear discontinuities in the dataset and that limiting the maximum material stress to the yield stress is overly conservative for stocky cross-sections. The ultimate bending moments from the collected beam tests normalised by the elastic moment $\left(M_{u} / M_{e l}\right)$ are plotted in Fig. 2 against the cross-section slenderness. As for compression, in contrast to the EN 1993-1-1 [2] resistance line, there are no apparent discontinuities in the bending capacity dataset that cross-section classification would otherwise suggest and again limiting the material stress to the yield stress can lead to under-predictions of the ultimate cross-section capacity for stocky sections. The results show that the previous yield slenderness limit of $\bar{\lambda}_{c}=0.3$ can also be applied for bending.

\subsection{Normalised deformation capacity (strain ratio)}

In the CSM, cross-section classification is replaced by a continuous relationship between local slenderness and deformation capacity. This deformation capacity is called the strain ratio $\left(\varepsilon_{c s m} / \varepsilon_{y}\right)$ and is defined as the strain at ultimate load 


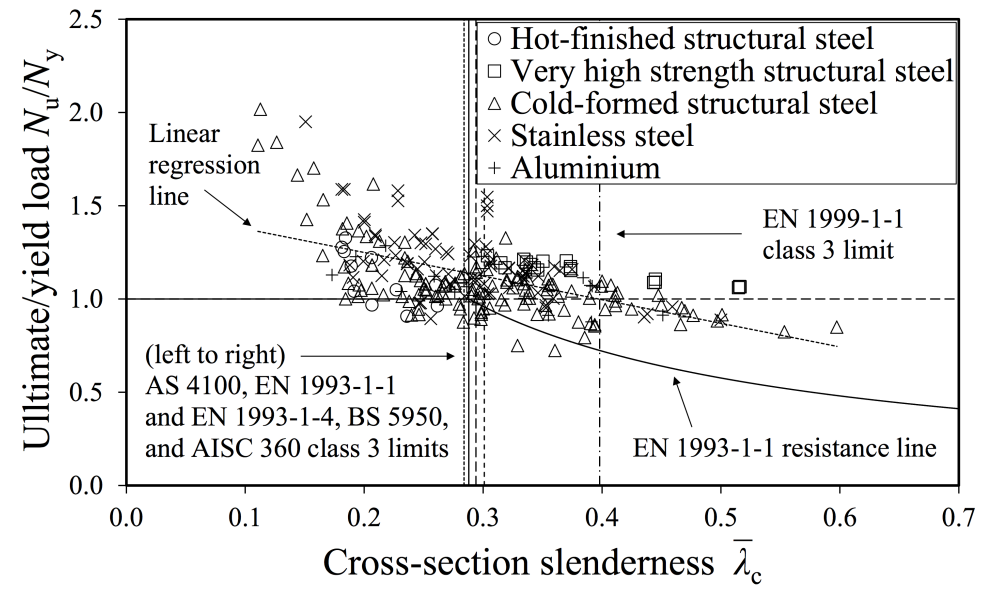

Figure 1: Normalised ultimate axial resistance $N_{u} / N_{y}$ varying with local slenderness $\bar{\lambda}_{c}$.

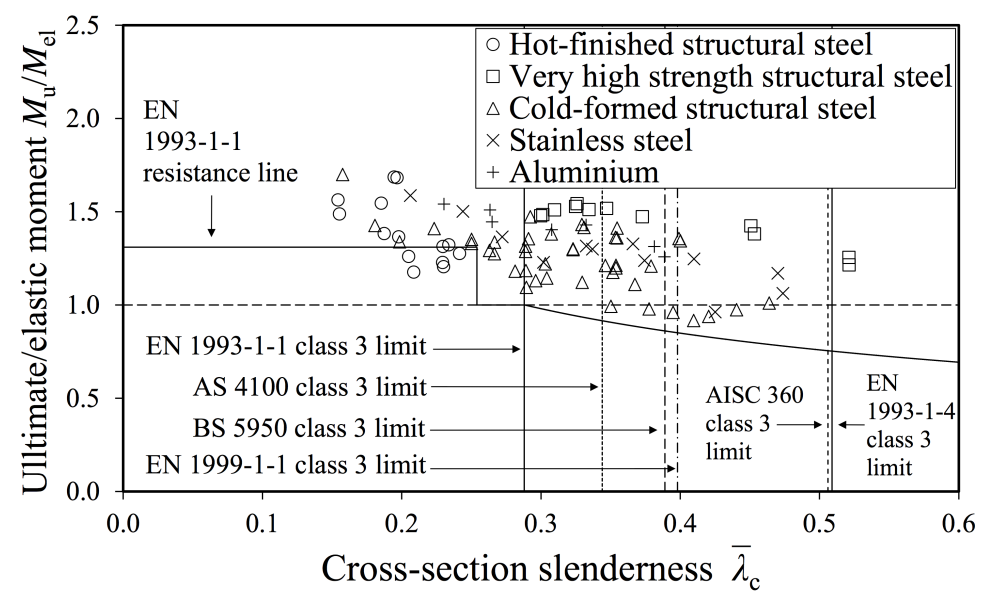

Figure 2: Normalised ultimate flexural resistance $M_{u} / M_{e l}$ varying with local slenderness $\bar{\lambda}_{c}$. 
$\varepsilon_{c s m}$, which is taken as the limiting strain for the cross-section, normalised by the yield strain $\varepsilon_{y}$. The strain ratio is determined from stub column and fourpoint bending experiments, as described below.

\subsubsection{Axial compression}

For stub columns with a local slenderness below the yield slenderness limit $\left(\bar{\lambda}_{c} \leq 0.3\right)$ and where the ultimate load exceeds the yield load $\left(N_{u} \geq N_{y}\right)$, the strain ratio is expressed as a function of the strain at ultimate load divided by the yield strain $\left(\varepsilon_{l b} / \varepsilon_{y}\right)$ (Eqs. 3 and 4 ). The strain at ultimate load $\varepsilon_{l b}$ can be calculated from the initial specimen length $L$ and the end-shortening $\delta_{u}$ at the ultimate load $N_{u}$. A 0.002 strain offset is subtracted from $\varepsilon_{l b}$ for materials with a rounded stress-strain response for compatibility with the material models adopted in Section 2.6, as shown in Eq. 3.

For $\bar{\lambda}_{c} \leq 0.3, N_{u} \geq N_{y}$ and a rounded material response:

$$
\frac{\varepsilon_{c s m}}{\varepsilon_{y}}=\frac{\varepsilon_{l b}-0.002}{\varepsilon_{y}}=\frac{\delta_{u} / L-0.002}{\varepsilon_{y}}
$$

For $\bar{\lambda}_{c} \leq 0.3, N_{u} \geq N_{y}$ and a sharply defined yield point:

$$
\frac{\varepsilon_{c s m}}{\varepsilon_{y}}=\frac{\varepsilon_{l b}}{\varepsilon_{y}}=\frac{\delta_{u} / L}{\varepsilon_{y}}
$$

For specimens that do not exceed the yield load $\left(N_{u}<N_{y}\right)$ or that have slender cross-sections $\left(\bar{\lambda}_{c}>0.3\right)$, the strain ratio is determined as the ratio of the ultimate load to yield load $\left(N_{u} / N_{y}\right)$, as given by Eq. 5 .

For $\bar{\lambda}_{c}>0.3$ or $N_{u}<N_{y}$

$$
\frac{\varepsilon_{c s m}}{\varepsilon_{y}}=\frac{N_{u}}{N_{y}}
$$

\subsubsection{Four-point bending}

Under uniform bending, the strain can be determined as the product of the curvature $\kappa$ and the distance from the elastic neutral axis $y$ (Eq. 6); the curvature at the ultimate moment and the elastic moment are termed $\kappa_{u}$ and $\kappa_{e l}$ 
respectively.

$$
\varepsilon=\kappa y
$$

$\kappa_{u}$ can be calculated from existing four-point bending experimental data using Eq. 7 [78.

$$
\kappa=\frac{1}{r}=\frac{8\left(D_{M}-D_{L}\right)}{4\left(D_{M}-D_{L}\right)^{2}+L_{2}^{2}}
$$

where $r$ is the radius of curvature, $D_{M}$ and $D_{L}$ are the displacements at the midspan and loading points respectively and $L_{2}$ is the length of the central region of the beam between the two loading points. The curvature at the elastic moment $\kappa_{e l}$ can be determined from Eq. 8, where $I$ is the second moment of area.

$$
\kappa_{e l}=\frac{M_{e l}}{E I}
$$

The strain ratio for four-point bending is similar in principle to axial compression, being defined as a function of the maximum strain in the cross-section at the ultimate moment normalised by the yield strain $\left(\varepsilon_{l b} / \varepsilon_{y}\right)$ for $\bar{\lambda}_{c} \leq 0.3$ and where the ultimate moment exceeds the elastic moment $\left(M_{u} \geq M_{e l}\right)$ (Eqs. 9 and 10). The 0.002 offset is again subtracted for materials with a rounded stress-strain response as shown in Eq. 9, where $y_{\max }$ is the distance from the elastic neutral axis to the extreme fibre of the cross-section.

For $\bar{\lambda}_{c} \leq 0.3, M_{u} \geq M_{e l}$ and a rounded material response:

$$
\frac{\varepsilon_{c s m}}{\varepsilon_{y}}=\frac{\varepsilon_{l b}-0.002}{\varepsilon_{y}}=\frac{\kappa_{u} y_{\max }-0.002}{\kappa_{e l} y_{\max }}
$$

For $\bar{\lambda}_{c} \leq 0.3, M_{u} \geq M_{e l}$ and a sharply defined yield point:

$$
\frac{\varepsilon_{c s m}}{\varepsilon_{y}}=\frac{\varepsilon_{l b}}{\varepsilon_{y}}=\frac{\kappa_{u} y_{\max }}{\kappa_{e l} y_{\max }}
$$

If the cross-section is slender $\left(\bar{\lambda}_{c}>0.3\right)$ or the ultimate moment is less than the elastic moment $\left(M_{u}<M_{e l}\right)$, the strain ratio is taken as the ultimate moment normalised by the elastic moment $\left(M_{u} / M_{e l}\right)$, as shown in Eq. 11 . 
For $\bar{\lambda}_{c}>0.3$ or $M_{u}<M_{e l}$

$$
\frac{\varepsilon_{c s m}}{\varepsilon_{y}}=\frac{M_{u}}{M_{e l}}
$$

\subsection{Base curve}

The base curve defines the relationship between the deformation capacity of a cross-section (i.e. the maximum limiting strain that it can endure $\varepsilon_{c s m}$ ) and the local slenderness of the cross-section. Base curves for non-slender $\left(\bar{\lambda}_{c} \leq 0.3\right)$ and slender $\left(\bar{\lambda}_{c}>0.3\right)$ CHS with the forms of Eqs. 12 and 13 respectively can be fitted to the experimental strain ratios derived from the axial and bending results from the literature (Table 1), as plotted in Figs. 3 and 4 .

$$
\begin{gathered}
\frac{\varepsilon_{c s m}}{\varepsilon_{y}}=\frac{A}{\bar{\lambda}_{c}{ }^{B}} \text { for } \bar{\lambda}_{c} \leq 0.3 \\
\frac{\varepsilon_{c s m}}{\varepsilon_{y}}=\left(1-\frac{F}{\bar{\lambda}_{c}{ }^{G}}\right) \frac{1}{\bar{\lambda}_{c}{ }^{G}} \text { for } \bar{\lambda}_{c}>0.3
\end{gathered}
$$

Eq. 12 is consistent with previous implementations of the CSM (refer to Section 1.2), and is similar in form to the relationship between normalised elastic buckling strain $\varepsilon_{c r} / \varepsilon_{y}$ and local slenderness $\bar{\lambda}_{c}$, given by Eq. 14 . Eq. 13 is of the same general form as the normalised strength curves from the Direct Strength Method (DSM) [79].

$$
\frac{\varepsilon_{c r}}{\varepsilon_{y}}=\frac{1}{\bar{\lambda}_{c}^{2}}
$$

The two chosen base curves, given by Eq. 15 for non-slender CHS and by Eq. 16 for slender CHS, generally represent a lower bound to the dataset and meet at the yield slenderness limit $\left(\bar{\lambda}_{c}=0.3\right)$ previously identified at a strain ratio $\varepsilon_{c s m} / \varepsilon_{y}$ of unity.

$$
\begin{gathered}
\frac{\varepsilon_{c s m}}{\varepsilon_{y}}=\frac{4.44 \times 10^{-3}}{\bar{\lambda}_{c}^{4.5}} \text { for } \bar{\lambda}_{c} \leq 0.3 \text { but } \frac{\varepsilon_{c s m}}{\varepsilon_{y}} \leq \min \left(15, \frac{C_{1} \varepsilon_{u}}{\varepsilon_{y}}\right) \\
\frac{\varepsilon_{c s m}}{\varepsilon_{y}}=\left(1-\frac{0.224}{\bar{\lambda}_{c}^{0.342}}\right) \frac{1}{\bar{\lambda}_{c}^{0.342}} \text { for } 0.3<\bar{\lambda}_{c} \leq 0.6
\end{gathered}
$$




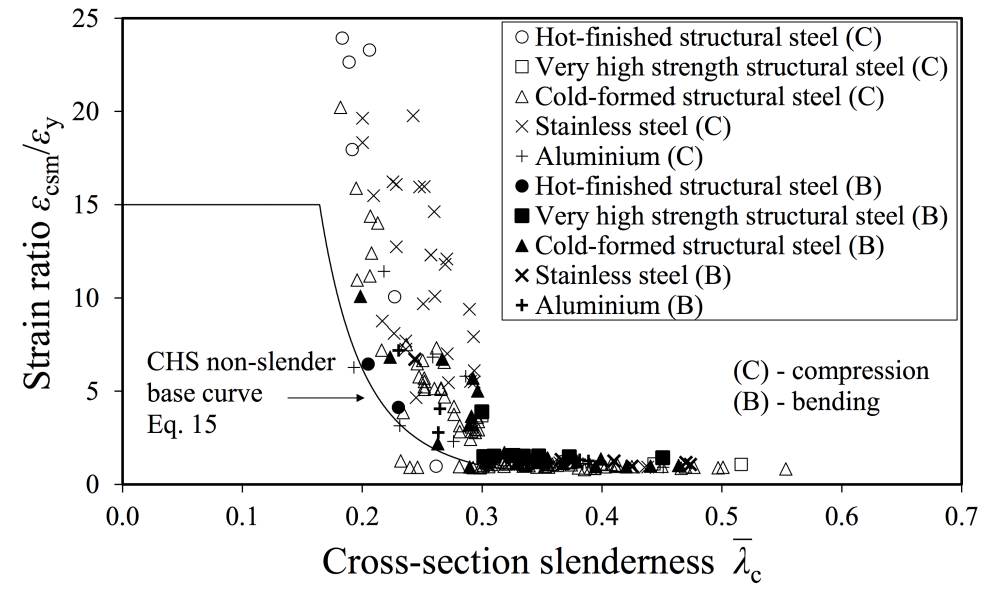

Figure 3: CHS CSM non-slender base curve with collected experimental data.

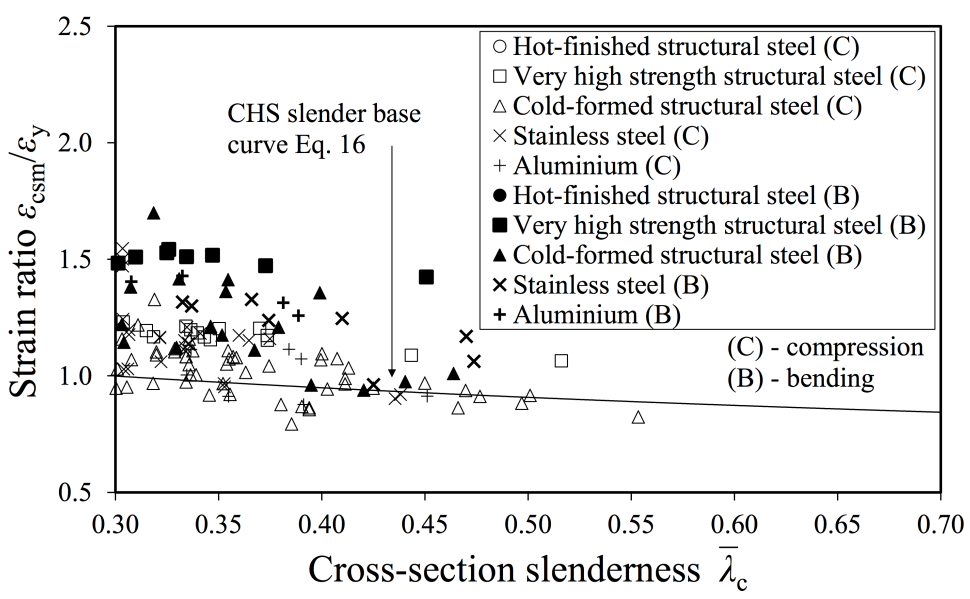

Figure 4: CHS CSM slender base curve with collected experimental data. 
Upper limits are placed upon the strain ratio, in effect limiting the extent to which the non-slender cross-sections can deform. The upper limit of 15 in Eq. 15 is the material ductility requirement from EN 1993-1-1 [2] and is applied to all metallic materials. A second upper limit is applied to cold-formed and very high strength structural steel $\left(C_{1}=0.4\right)$, austenitic and duplex stainless steel $\left(C_{1}=0.1\right)$, ferritic stainless steel $\left(C_{1}=0.4\right)$ and aluminium $\left(C_{1}=0.5\right)$ to prevent over-predictions of cross-section resistance due to the chosen simplified material model. $\varepsilon_{u}$ is the strain at the ultimate tensile stress of the material, and is discussed further in Section 2.6. An upper limit of $\bar{\lambda}_{c} \leq 0.6$ is placed upon the slender base curve since experimental data has not been examined beyond this slenderness.

\subsection{Material models}

An elastic, linear strain hardening material model (of slope $E_{s h}$ ), as shown in Fig. 5. is adopted in the CSM, replacing the traditional elastic, perfectly-plastic material model typically employed in existing design codes. The coefficients $C_{1}$ to $C_{4}$ are defined in Section 2.6.5. The CSM limiting stress $f_{c s m}$ is defined by Eq. 17 for $\varepsilon_{c s m} / \varepsilon_{y}<1$ and by Eq. 18 for $\varepsilon_{c s m} / \varepsilon_{y} \geq 1$. Eq. 18 represents the strain hardening behaviour of the material through the strain hardening modulus $E_{s h}$.

$$
\begin{gathered}
f_{c s m}=E \varepsilon_{c s m} \text { for } \frac{\varepsilon_{c s m}}{\varepsilon_{y}}<1 \\
f_{c s m}=f_{y}+E_{s h} \varepsilon_{y}\left(\frac{\varepsilon_{c s m}}{\varepsilon_{y}}-1\right) \text { for } \frac{\varepsilon_{c s m}}{\varepsilon_{y}} \geq 1
\end{gathered}
$$

\subsubsection{Hot-finished structural steel sections}

For hot-finished structural steel sections, the strain hardening modulus $E_{s h}$ proposed by Foster [10] has been utilised. This is the simplest model adopted as strain hardening is taken as zero (Eq. 19), reducing the stress-strain response to the traditional linear elastic, perfectly-plastic model. This is due to the extensive yield plateau associated with hot-finished tubes. Work is currently underway to develop a more refined material model for hot-finished structural steel sections 


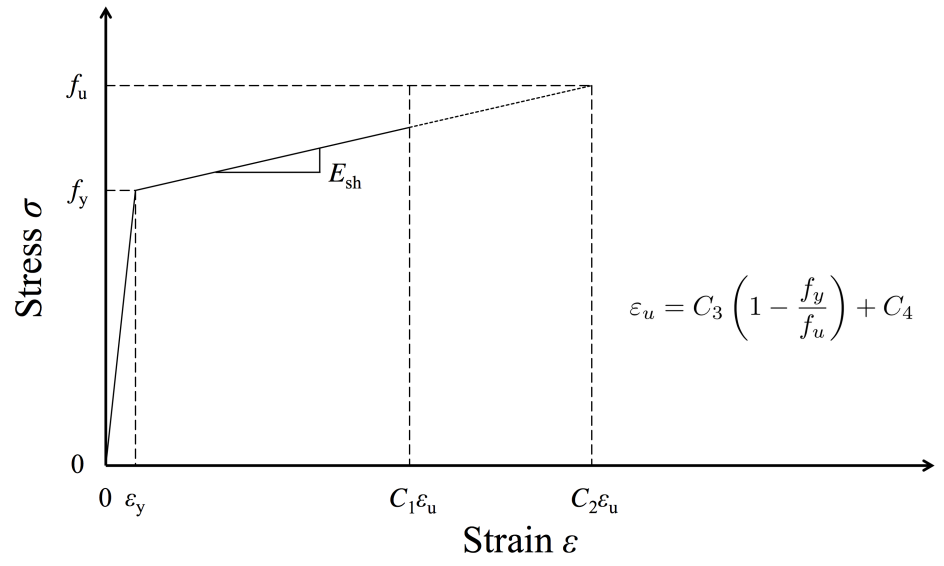

Figure 5: Elastic, linear strain hardening CSM material model.

that takes into account strain hardening at the end of the yield plateau, leading to strain hardening benefits for cross-sections with high deformation capacities.

$$
\frac{E_{s h}}{E}=0
$$

\subsubsection{Cold-formed structural steel sections}

For cold-formed structural steel sections, based on recent work by Gardner et 185 al. 80, the strain hardening modulus $E_{s h}$ is defined by Eqs. 20 and 21, depending on the ratio $\varepsilon_{y} / \varepsilon_{u}$. This model is also applied to the very high strength structural steel CHS considered herein.

For $\varepsilon_{y} / \varepsilon_{u}<0.45$ :

$$
E_{s h}=\frac{f_{u}-f_{y}}{0.45 \varepsilon_{u}-\varepsilon_{y}}
$$

For $\varepsilon_{y} / \varepsilon_{u} \geq 0.45$ :

$$
E_{s h}=0
$$

The material strain $\varepsilon_{u}$ corresponding to the ultimate tensile stress $f_{u}$ may be predicted using Eq. 22 [80].

$$
\varepsilon_{u}=0.6\left(1-\frac{f_{y}}{f_{u}}\right)
$$




\subsubsection{Stainless steel sections}

For stainless steel sections, the material model developed by Afshan and Gardner [11] is utilised for the austenitic and duplex grades. The strain hardening modulus $E_{s h}$ is predicted from Eq. 23 and $\varepsilon_{u}$ is given by Eq. 24, which is taken from EN 1993-1-4 [4, 81]. The ultimate tensile stress $f_{u}$, if not provided, can be estimated using Eq. 25 81.

$$
\begin{gathered}
E_{s h}=\frac{f_{u}-f_{y}}{0.16 \varepsilon_{u}-\varepsilon_{y}} \\
\varepsilon_{u}=1-\frac{f_{y}}{f_{u}} \\
f_{u}=\frac{f_{y}}{0.2+185 f_{y} / E}
\end{gathered}
$$

The material model developed by Bock et al. 82 has been applied to the ferritic grades. This model is the same as that proposed for cold-formed structural steel sections, and therefore utilises Eqs. 20, 21 and 22 [82. If $f_{u}$ is not provided it can be predicted using Eq. 26 83, 84].

$$
f_{u}=\frac{f_{y}}{0.46+145 f_{y} / E}
$$

\subsubsection{Aluminium sections}

For aluminium alloy sections, the material model proposed by Su et al. [12] is adopted in this study. The predictive expression for the strain hardening modulus $E_{s h}$ is given by Eq. 27. This is similar in form to the previous coldformed structural steel and stainless steel models. The material ultimate strain $\varepsilon_{u}$ may be predicted from Eq. 28 . The latter expression is only applicable when the ratio of the ultimate stress $f_{u}$ to yield stress $f_{y}$ exceeds 1.01 .

$$
E_{s h}=\frac{f_{u}-f_{y}}{0.5 \varepsilon_{u}-\varepsilon_{y}}
$$

For $f_{u} / f_{y}>1.01$

$$
\varepsilon_{u}=0.13\left(1-\frac{f_{y}}{f_{u}}\right)+0.06
$$




\begin{tabular}{lcccc}
\hline & $C_{1}$ & $C_{2}$ & $C_{3}$ & $C_{4}$ \\
\hline Hot-finished structural steel & -1 & -1 & $-{ }^{1}$ & $-{ }^{1}$ \\
Very high strength structural steel & 0.40 & 0.45 & 0.60 & 0 \\
Cold-formed structural steel & 0.40 & 0.45 & 0.60 & 0 \\
Austenitic and duplex stainless steel & 0.10 & 0.16 & 1.00 & 0 \\
Ferritic stainless steel & 0.40 & 0.45 & 0.60 & 0 \\
Aluminium & 0.50 & 0.50 & 0.13 & 0.06 \\
\hline
\end{tabular}

${ }^{1}$ Hot-finished structural steel material model under development

Table 3: Summary of coefficients for the CSM material model.

\subsubsection{Summary of material models}

The CSM provides a harmonised design approach across all metallic materials. A common base curve (Eqs. 15 and 16) is used for CHS of all materials, while the differing strain hardening characteristics of the various materials are accounted for through different coefficients in the general elastic, linear hardening $\sigma-\varepsilon$ curve (see Fig. 5). There are four coefficients $C_{1}, C_{2}, C_{3}$ and $C_{4} . C_{1}$ defines a 'cut-off' strain (in Eq. 15) to avoid over-predictions of material strength when using the elastic, linear hardening material model; $C_{2}$ is used in Eq. 29 to define the strain hardening slope $E_{s h}$; and $C_{3}$ and $C_{4}$ are used in the predictive expression for ultimate strain (Eq. 30), which is also needed to determine $E_{s h}$. Values of the coefficients for the different considered materials are summarised in Table 3 ,

$$
\begin{gathered}
E_{s h}=\frac{f_{u}-f_{y}}{C_{2} \varepsilon_{u}-\varepsilon_{y}} \\
\varepsilon_{u}=C_{3}\left(1-\frac{f_{y}}{f_{u}}\right)+C_{4}
\end{gathered}
$$




\section{CSM cross-section resistance functions for CHS}

The cross-section resistances in compression or bending can now be determined

utilising the deformation capacity $\left(\varepsilon_{c s m} / \varepsilon_{y}\right)$ predicted from the base curve, together with the adopted material model.

\subsection{Compressive resistance}

The CSM axial compressive resistance for non-slender cross-sections $N_{c s m}$ is calculated as the product of the gross cross-section area $A$ and the CSM limiting material stress $f_{c s m}$, as given by Eq. 31 .

$$
N_{c s m}=A f_{c s m} \text { for } \bar{\lambda}_{c} \leq 0.3
$$

The strength benefit for non-slender cross-sections arises when the CSM limiting stress $f_{c s m}$ exceeds the yield stress $f_{y}$. Consequently for hot-finished structural steel sections there are no strength benefits due to the strain hardening model adopted in Eq. 19, while for the other considered materials, there is additional resistance with increasing deformation capacity.

For slender cross-sections, the axial compressive resistance can be determined using Eq. 32 , which is the yield load $A f_{y}$ factored by the strain ratio.

$$
N_{c s m}=\frac{\varepsilon_{c s m}}{\varepsilon_{y}} A f_{y} \text { for } 0.3<\bar{\lambda}_{c} \leq 0.6
$$

\subsection{Bending resistance}

215 The derivation of the CSM bending resistance function for non-slender CHS 85] is first described. In the derivation, it is assumed that plane sections remain plane and normal to the neutral axis during bending, and that the cross-section shape does not significantly distort before the outer-fibre strain $\varepsilon_{c s m}$ is attained. The corresponding linear strain and bi-linear stress distributions (arising for the elastic, linear hardening material model) for half of a CHS are shown in Fig. 6 . 


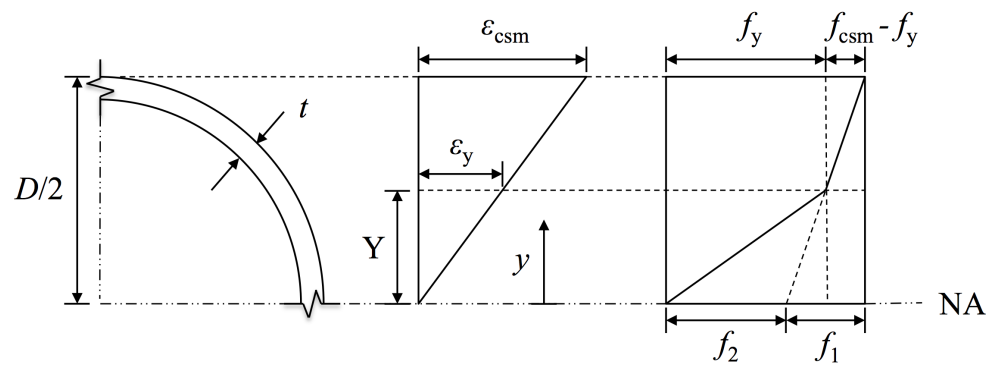

Figure 6: Strain and stress profiles for half of a CHS (a quarter of the cross-section is shown).

From Fig. 6, the bending capacity of a cross-section can be expressed by Eq. 33 in terms of the elastic section modulus $W_{e l}$, plastic section modulus $W_{p l}$, and the introduced modulus $W_{w}$.

$$
M_{c s m}=W_{p l} f_{c s m}-\left(W_{p l}-W_{e l}\right) f_{1}-W_{w} f_{2}
$$

The term $W_{w} f_{2}$ represents the moment caused by the triangular shaped stress block associated with stress $f_{2}$ for $|y| \leq Y$. The first yield distance $Y$ from the neutral axis NA is given by Eq. 34 .

$$
Y=\frac{0.5 D}{\varepsilon_{c s m} / \varepsilon_{y}}
$$

Using the CSM material model (Eq. 18 from Section 2.6) and the stress distribution geometry in Fig. 6, stresses $f_{1}$ and $f_{2}$ are determined as follows.

$$
\begin{gathered}
\frac{f_{1}}{f_{y}}=\frac{E_{s h}}{E} \frac{\varepsilon_{c s m}}{\varepsilon_{y}} \\
\frac{f_{2}}{f_{y}}=1-\frac{E_{s h}}{E}
\end{gathered}
$$

Normalising Eq. 33 by the plastic moment capacity $M_{p l}=W_{p l} f_{y}$ and substituting in the expressions for $f_{c s m}, f_{1}$ and $f_{2}$ gives Eq. 37 .

$$
\frac{M_{c s m}}{M_{p l}}=1+\frac{E_{s h}}{E}\left(\frac{\varepsilon_{c s m}}{\varepsilon_{y}} \frac{W_{e l}}{W_{p l}}-1\right)-\frac{W_{w}}{W_{p l}}\left(1-\frac{E_{s h}}{E}\right)
$$

The moment $M_{f_{2}}=W_{w} f_{2}$ is defined in Eq. 38, from which the introduced modulus $W_{w}$ can be determined using Eq. 39 , where the function $g(y)$ represents the 


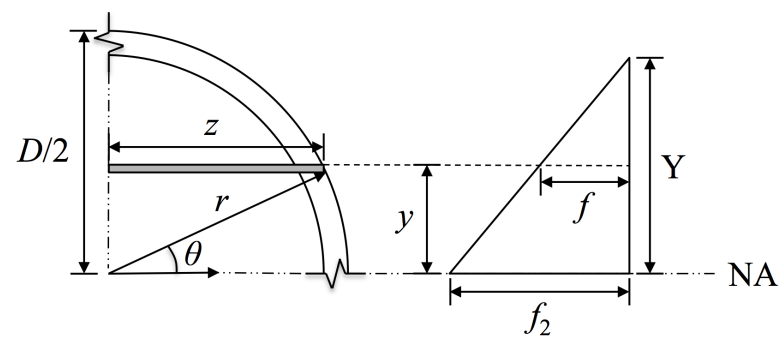

Figure 7: Geometry for the derivation of $W_{w}$ for CHS.

triangular stress distribution normalised by $f_{2}$. The integral is only evaluated to the first yield point $|y|=Y$, and the associated area to integrate over is $A_{Y}$.

$$
\begin{gathered}
M_{f_{2}}=W_{w} f_{2}=\int_{A_{Y}} f y \mathrm{~d} A_{Y}=\int_{A_{Y}} f_{2} g(y) y \mathrm{~d} A_{Y} \\
W_{w}=\int_{A_{Y}} g(y) y \mathrm{~d} A_{Y}
\end{gathered}
$$

If integration is performed over one quarter of the cross-section, as in Fig. 7, then the result may be multiplied by four for the entire CHS to give the modulus $W_{w}$ corresponding to the area $A_{Y}$. From the equation of a circle (Eq. 40, in $z$ and $y$ co-ordinates and with radius $r$, the positive branch length can be calculated from Eq. 41

$$
\begin{gathered}
z^{2}+y^{2}=r^{2} \\
z=r \sqrt{1-\frac{y^{2}}{r^{2}}} .
\end{gathered}
$$

The introduced modulus $W_{w, r}$ for a solid circle of radius $r$ can be determined from Eq. 42, which is four times the integral of the stress triangle multiplied by the associated area and lever arm.

$$
W_{w, r}=4 \int_{0}^{Y} y\left(1-\frac{y}{Y}\right) z \mathrm{~d} y=4 r \int_{0}^{Y} y \sqrt{1-\frac{y^{2}}{r^{2}}} \mathrm{~d} y-\frac{4 r}{Y} \int_{0}^{Y} y^{2} \sqrt{1-\frac{y^{2}}{r^{2}}} \mathrm{~d} y
$$

where $Y$ from Eq. 34 is the value of $y$ at first yield, which is constant for a given 
strain ratio. The solution to this integral is given by Eq. 43 .

$W_{w, r}=\frac{4 r^{3}}{3}\left[1-\left(1-\frac{Y^{2}}{r^{2}}\right)^{\frac{3}{2}}\right]-\frac{r}{Y}\left[\frac{Y}{2}\left(2 Y^{2}-r^{2}\right) \sqrt{1-\frac{Y^{2}}{r^{2}}}+\frac{r^{3}}{2} \sin ^{-1}\left(\frac{Y}{r}\right)\right]$

$W_{w}$ for a circular hollow section can then be calculated from $W_{w}=W_{w, r_{2}}$ $W_{w, r_{1}}$, where $W_{w, r_{2}}$ is evaluated for the outer radius $r_{2}=D / 2$, leading to Eq. 44, and $W_{w, r_{1}}$ is determined for the inner radius $r_{1}=r_{2}-t$, leading to Eq. 45 .

$$
\begin{aligned}
& W_{r, r 2}=\frac{4 r_{2}^{3}}{3}\left[1-\cos ^{3} \alpha\right]-\frac{r_{2}^{3}}{\sin \alpha}\left[\sin ^{3} \alpha \cos \alpha+\frac{\alpha}{2}-\frac{\sin \alpha \cos \alpha}{2}\right] \\
& W_{r, r 1}=\frac{4 r_{1}^{3}}{3}\left[1-\cos ^{3} \beta\right]-\frac{r_{1}^{3}}{\sin \beta}\left[\sin ^{3} \beta \cos \beta+\frac{\beta}{2}-\frac{\sin \beta \cos \beta}{2}\right]
\end{aligned}
$$

where $\sin \alpha=\frac{Y}{r_{2}}, \cos \alpha=\sqrt{1-\frac{Y^{2}}{r_{2}{ }^{2}}}, \sin \beta=\frac{Y}{r_{1}}$ and $\cos \beta=\sqrt{1-\frac{Y^{2}}{r_{1}{ }^{2}}}$. The analytical formula is valid for $r_{2} / r_{1}<\varepsilon_{c s m} / \varepsilon_{y}$.

Substituting $W_{w}=W_{w, r_{2}}-W_{w, r_{1}}$ and the expressions for the two introduced moduli into Eq. 37 leads to the exact analytical CSM bending resistance function. However, due to the lengthy $W_{w}$ term, the exact expression is not suitable for use in design, and therefore a simplified design equation is sought.

For a strain ratio $\varepsilon_{c s m} / \varepsilon_{y}$ of unity, $f_{c s m}=f_{y}$, and the introduced modulus $W_{w}$ simplifies to:

$$
W_{w}=W_{p l}-W_{e l}
$$

For strain ratios greater than unity, the introduced modulus $W_{w}$ can be approximated by Eq. 47 [8, which can then be substituted into Eq. 37 to give the normalised CSM moment capacity expressed by Eq. 48 .

$$
\begin{gathered}
W_{w}=\left(W_{p l}-W_{e l}\right) /\left(\frac{\varepsilon_{c s m}}{\varepsilon_{y}}\right)^{2} \\
\frac{M_{c s m}}{M_{p l}}=1+\frac{E_{s h}}{E}\left(\frac{\varepsilon_{c s m}}{\varepsilon_{y}} \frac{W_{e l}}{W_{p l}}-1\right)-\left(1-\frac{W_{e l}}{W_{p l}}\right)\left(1-\frac{E_{s h}}{E}\right) /\left(\frac{\varepsilon_{c s m}}{\varepsilon_{y}}\right)^{2}
\end{gathered}
$$


By noting that in general $E_{s h} / E<<1$, the $\left(1-E_{s h} / E\right)$ term can conservatively be taken as unity as the final term is subtractive, while the remaining expression can be forced through $M_{e l}$ at a strain ratio of unity to give the simplified $M_{c s m}$ equation provided as Eq. 49 .

$M_{c s m}=M_{p l}\left[1+\frac{E_{s h}}{E} \frac{W_{e l}}{W_{p l}}\left(\frac{\varepsilon_{c s m}}{\varepsilon_{y}}-1\right)-\left(1-\frac{W_{e l}}{W_{p l}}\right) /\left(\frac{\varepsilon_{c s m}}{\varepsilon_{y}}\right)^{2}\right]$ for $\bar{\lambda}_{c} \leq 0.3$

Design equations of this format have also been used for determining the CSM bending resistance of I-sections and box sections [9]. The exact analytical CSM bending resistance expression, Eq. 37, is plotted along with the simplified CSM design expression, Eq. 49 , in Fig. 8 for a typical ratio of $E s h / E$ of $1 / 100$. The design equation can be seen to tend towards the analytical expression for the higher strain ratios where $W_{w}$ has a smaller influence, and that, overall, the difference between the two curves is minimal.

The variation in bending capacity $M_{c s m} / M_{p l}$ with strain ratio $\varepsilon_{c s m} / \varepsilon_{y}$ for various strain hardening ratios $E_{s h} / E$ is plotted in Fig. 9. The bending capacity 240 at a strain ratio of unity is the elastic moment $M_{e l}$. The subsequent increase in bending capacity for $\varepsilon_{c s m} / \varepsilon_{y}>1$ is dependent upon the strain hardening ratio, where a larger strain hardening modulus leads to a greater increase in bending capacity with increasing strain ratio $\varepsilon_{c s m} / \varepsilon_{y}$. If the strain hardening modulus is taken as zero, the bending capacity is asymptotic to the plastic moment capacity. It should be noted that the CSM bending resistance function for CHS is sensitive to the strain ratio in the region of $\varepsilon_{c s m} / \varepsilon_{y}<3$, reflecting the relatively high shape factor of CHS and the marked increases in moment capacity that arise during the initial spread of plasticity.

For slender cross-sections the CSM bending resistance $M_{c s m}$ can be calculated by factoring the elastic moment capacity $W_{e l} f_{y}$ by the strain ratio as shown in 


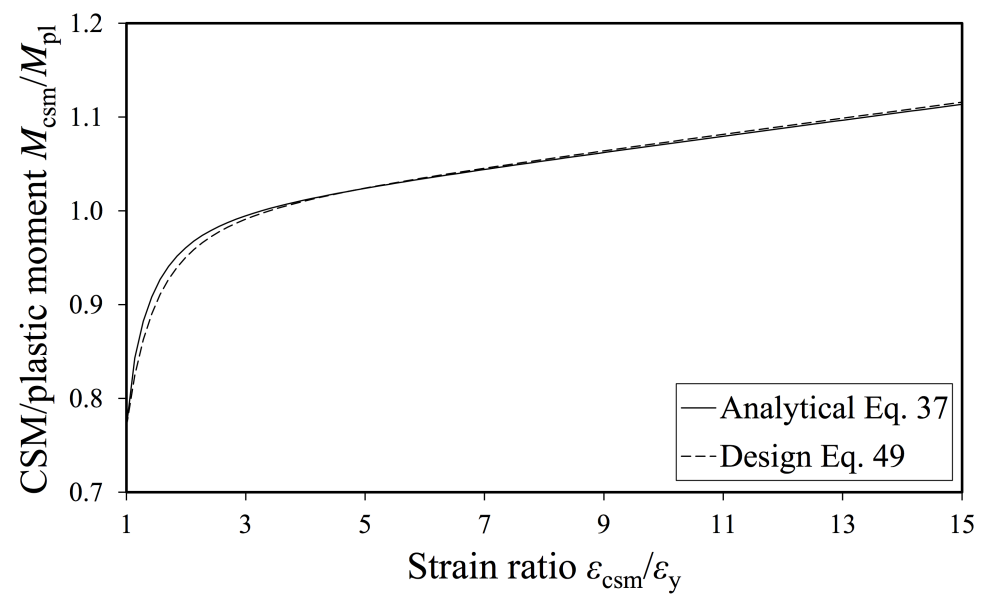

Figure 8: Comparison between exact and approximate (design) CSM bending capacity predictions $M_{c s m} / M_{p l}$ with varying $\varepsilon_{c s m} / \varepsilon_{y}$.

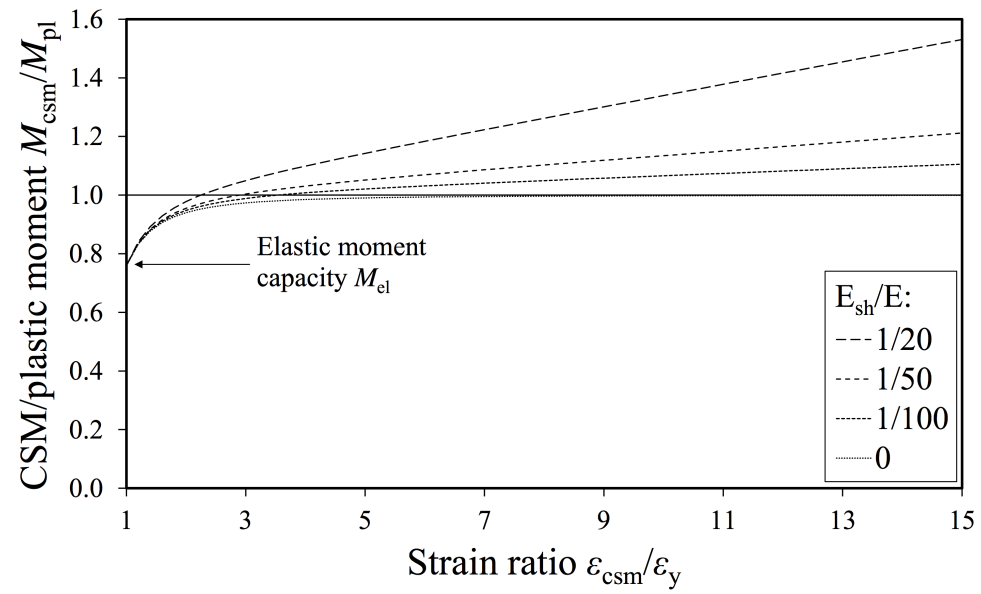

Figure 9: Influence of $E_{s h} / E$ on $M_{c s m} / M_{p l}$ with varying $\varepsilon_{c s m} / \varepsilon_{y}$. 
Eq. 50 .

$$
M_{c s m}=\frac{\varepsilon_{c s m}}{\varepsilon_{y}} W_{e l} f_{y} \text { for } 0.3<\bar{\lambda}_{c} \leq 0.6
$$

\section{Comparison with test data and existing design methods}

The CSM predictions for compression and bending resistances have been compared with the measured ultimate values from the collected experiments. The average ultimate test loads $N_{u}$ and moments $M_{u}$ normalised by the CSM ( $N_{c s m}$, $\left.M_{c s m}\right)$ and Eurocode $\left(N_{E C}, M_{E C}\right)$ predictions have been determined for each material type and are summarised in Tables 4 and 6 respectively for non-slender cross-sections $\left(\bar{\lambda}_{c} \leq 0.3\right)$, and in Tables 5 and 7 for slender cross-sections $\left(\bar{\lambda}_{c}>0.3\right)$. EN 1993-1-1 [2] and EN 1993-1-4 [4] do not provide design expressions for slender CHS in compression or bending; the design formulae for slender cross-sections from BS 5950-1 [3] with updated Eurocode class 3 limits have therefore been utilised [86]. EN 1999-1-1 [5] provides design expressions for slender class 4 aluminium CHS resistances in compression and bending. The coefficients of variation (COV) have also been calculated to quantify and allow comparisons of the scatter of the predictions. The ultimate experimental loads normalised by their CSM and Eurocode predictions $\left(N_{u, p r e d}, M_{u, p r e d}\right)$ have been plotted for compression in Fig. 10 and bending in Fig. 11 .

Overall, on average, for both non-slender and slender cross-sections the CSM predicts cross-section compression and bending resistances that are more accurate and consistent compared with those from the Eurocodes. Looking initially at the non-slender predictions, apart from for hot-finished structural steel, the CSM predictions are on average closer to the measured ultimate resistance than those from the Eurocodes and exhibit reduced scatter. For hot-finished structural steel, the CSM and EN 1993-1-1 [2] predictions are the same for crosssections in compression (due to the use of $E_{s h}=0$ ), while in bending the CSM is more conservative than EN 1993-1-1 2] as the predicted capacity does not 


\begin{tabular}{lllll}
\hline Material & Mean & \multicolumn{3}{l}{ COV } \\
& $N_{u} / N_{c s m}$ & $N_{u} / N_{E C}$ & $N_{u} / N_{c s m}$ & $N_{u} / N_{E C}$ \\
\hline Hot-finished structural steel & 1.08 & 1.08 & 0.12 & 0.12 \\
Very high strength structural & 1.19 & 1.21 & -1 & -1 \\
steel & & & & \\
Cold-formed structural steel & 1.12 & 1.17 & 0.17 & 0.20 \\
Stainless steel & 1.19 & 1.26 & 0.12 & 0.16 \\
Aluminium & 1.09 & 1.13 & 0.08 & 0.08 \\
\hline Average & 1.14 & 1.19 & 0.14 & 0.18 \\
\hline
\end{tabular}

${ }^{1}$ Insufficient experimental data

Table 4: CSM and Eurocode compression resistance prediction comparison for $\bar{\lambda}_{c} \leq 0.3$.

\begin{tabular}{lllll}
\hline Material & Mean & \multicolumn{3}{l}{ COV } \\
& $N_{u} / N_{c s m}$ & $N_{u} / N_{E C}$ & $N_{u} / N_{c s m}$ & $N_{u} / N_{E C}$ \\
\hline Hot-finished structural steel & -1 & -1 & -1 & -1 \\
Very high strength structural & 1.20 & 1.50 & 0.02 & 0.13 \\
steel & & & & \\
Cold-formed structural steel & 1.04 & 1.27 & 0.10 & 0.14 \\
Stainless steel & 1.15 & 1.33 & 0.12 & 0.11 \\
Aluminium & 1.05 & 1.06 & 0.09 & 0.09 \\
\hline Average & 1.10 & 1.31 & 0.12 & 0.15 \\
\hline
\end{tabular}

${ }^{1}$ Insufficient experimental data

Table 5: CSM and Eurocode compression resistance prediction comparison for $0.3<\bar{\lambda}_{c} \leq 0.6$. 


\begin{tabular}{lllll}
\hline Material & Mean & \multicolumn{3}{l}{ COV } \\
& $M_{u} / M_{c s m}$ & $M_{u} / M_{E C}$ & $M_{u} / M_{c s m}$ & $M_{u} / M_{E C}$ \\
\hline Hot-finished structural steel & 1.06 & 1.05 & 0.11 & 0.12 \\
Very high strength structural & 1.47 & 1.49 & -1 & -1 \\
steel & & & & \\
Cold-formed structural steel & 1.10 & 1.18 & 0.10 & 0.12 \\
Stainless steel & 1.15 & 1.24 & 0.01 & 0.09 \\
Aluminium & 1.19 & 1.36 & 0.03 & 0.15 \\
\hline Average & 1.11 & 1.16 & 0.11 & 0.15 \\
\hline
\end{tabular}

${ }^{1}$ Insufficient experimental data

Table 6: CSM and Eurocode bending resistance prediction comparison for $\bar{\lambda}_{c} \leq 0.3$.

\begin{tabular}{lllll}
\hline Material & Mean & \multicolumn{3}{l}{ COV } \\
& $M_{u} / M_{c s m}$ & $M_{u} / M_{E C}$ & $M_{u} / M_{c s m}$ & $M_{u} / M_{E C}$ \\
\hline Hot-finished structural steel & -1 & -1 & -1 & -1 \\
Very high strength structural & 1.50 & 1.63 & 0.05 & 0.04 \\
steel & & & & \\
Cold-formed structural steel & 1.25 & 1.33 & 0.15 & 0.14 \\
Stainless steel & 1.26 & 1.21 & 0.09 & 0.10 \\
Aluminium & 1.39 & 1.39 & 0.04 & 0.03 \\
\hline Average & 1.32 & 1.38 & 0.13 & 0.15 \\
\hline
\end{tabular}

${ }^{1}$ Insufficient experimental data

Table 7: CSM and Eurocode bending resistance prediction comparison for $0.3<\bar{\lambda}_{c} \leq 0.6$. 


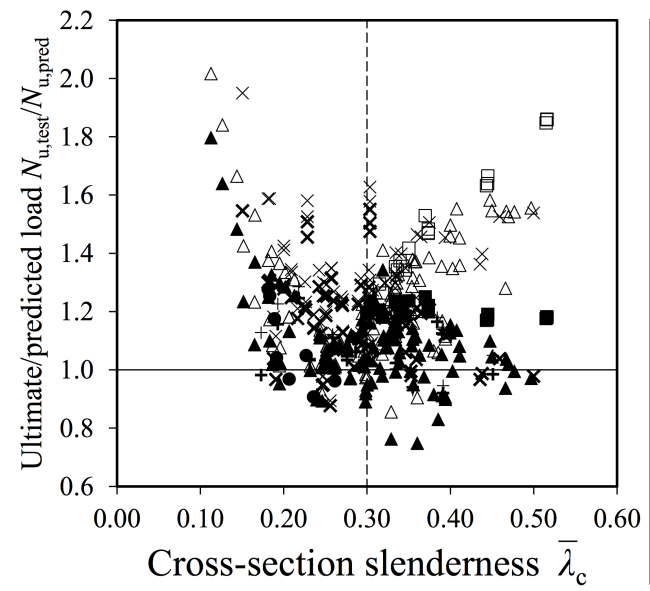

- Hot-finished structural steel (CSM)

- Hot-finished structural

steel (EC3)

- Very high strength

structural steel (CSM)

$\square$ Very high strength

structural steel (EC3)

$\Delta$ Cold-formed structural

steel (CSM)

$\triangle$ Cold-formed structural

steel (EC3)

$\times$ Stainless steel $(\mathrm{CSM})$

$\times$ Stainless steel (EC3)

+ Aluminium (CSM)

+ Aluminium (EC9)

Figure 10: CSM and Eurocode compression resistance prediction comparison.

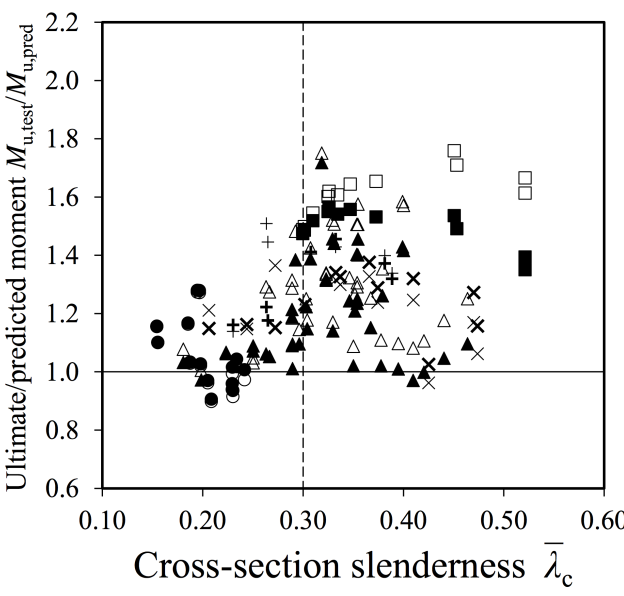

- Hot-finished structural steel (CSM)

o Hot-finished structural steel (EC3)

- Very high strength structural steel (CSM)

$\square$ Very high strength

structural steel (EC3)

$\Delta$ Cold-formed structural

steel (CSM)

$\triangle$ Cold-formed structural

steel (EC3)

$\times$ Stainless steel (CSM)

$\times$ Stainless steel (EC3)

+ Aluminium (CSM)

+ Aluminium (EC9)

Figure 11: CSM and Eurocode bending resistance prediction comparison. 
reach $M_{p l}$ and only approaches it asymptotically. Inspection of Fig. 11 reveals

\section{Conclusions}

The CSM has been extended to cover the design of CHS and has been seen to provide improved cross-section resistance predictions of between about $5 \%$ and 
$20 \%$ for different metallic materials over traditional design methods. For nonslender CHS $\left(\bar{\lambda}_{c} \leq 0.3\right)$ the CSM is generally more accurate and consistent in its capacity predictions and for slender CHS it also offers improved predictions of cross-section resistance, although with more scatter in some cases. The slender results $\left(\bar{\lambda}_{c}>0.3\right)$ are more varied primarily due to the differing, bespoke treatments across the various materials in existing design methods, compared to the standard, harmonised approach across all material types for the CSM. Further work is currently underway in refining the material models, with the aim to gain improved predictions over those currently attained, and undertaking reliability analyses. Improved predictions of CHS cross-section resistances will lead to lighter structures with more efficient material use, leading to more sustainable construction.

\section{References}

[1] Dutta D. Structures with hollow sections. Weinheim: Wiley VCH; 2002.

[2] European Committee for Standardisation (CEN) . EN 1993-1-1:2005 Eurocode 3: Design of steel structures - Part 1-1: General rules and rules for buildings. 2005 .

325

[3] British Standards Institution . BS 5950-1:2000 Structural use of steelwork in building - Part 1: Code of practice for design - Rolled and welded sections. 2000 .

[4] European Committee for Standardisation (CEN) . EN 1993-1-4:2006 Eurocode 3: Design of steel structures Part 1-4: General rules supplementary rules for stainless steel. 2006 .

[5] European Committee for Standardisation (CEN) . EN 1999-1-1:2007 Eurocode 9: Design of aluminium structures Part 1-1: General structural rules. 2007.

[6] American Institute of Steel Construction . ANSI/AISC 360-10 Specification for Structural Steel Buildings. 2010. 
[7] Standards Australia. AS 4100-1998 Steel Structures. 1998.

[8] Gardner L. The Continuous Strength Method. Proceedings of the Institution of Civil Engineers : Structures and Buildings 2008;161(3):127-33. doi $10.1680 /$ stbu.2008.161.3.127.

[9] Gardner L, Wang F, Liew A. Influence of Strain Hardening on the Behavior and Design of Steel Structures. International Journal of Structural Stability and Dynamics 2011;11(5):855-75. doi 10.1142/S0219455411004373.

[10] Foster A. Stability and design of steel beams in the strain-hardening range. Ph.D. thesis; Imperial College London; 2014.

[11] Afshan S, Gardner L. The continuous strength method for structural stainless steel design. Thin-Walled Structures 2013;68:42-9. doi:10.1016/j. tws.2013.02.011.

[12] Su MN, Young B, Gardner L. Testing and design of aluminum alloy cross sections in compression. Journal of Structural Engineering ASCE 2014;140(9). doi 10.1061/(ASCE)ST

[13] Liew A, Gardner L. Ultimate capacity of structural steel cross-sections under compression, bending and combined loading. Structures 2015;1:211. doi $10.1016 / j$.istruc. 2014.07 .001

[14] Buchanan C, Gardner L, Liew A. The continuous strength method for circular hollow sections. In: Batista E, Vellasco P, Lima L, editors. Proceedings of the 15th International Symposium on Tubular Structures. Rio de Janeiro: Balkema; 2015, p. 621-8.

[15] Timoshenko SP, Gere JM. Theory of elastic stability. Second ed.; McGrawHill Book Company; 1961.

[16] Donnell LH. A new theory for the buckling of thin cylinders under axial compression and bending. Transactions of the American Society of Mechanical Engineers 1934;56:795-806. 
[17] Gerard G, Becker H. Handbook of Structural Stability. Washington, D.C.: NACA; 1957.

[19] Seide P, Weingarten V. On the buckling of circular cylindrical shells under pure bending. ASME Journal of Applied Mechanics 1961;28(1):112-6.

[20] Reddy B, Calladine C. Classical bucking of a thin-walled tube subjected to

[21] Rotter JM, Sadowski AJ, Chen L. Nonlinear stability of thin elastic cylinders of different length under global bending. International Journal of 375 bending moment and internal pressure. International Journal of Mechanical Sciences 1978;20:641-50.

Solids and Structures 2014;51(15-16):2826-39. doi 10.1016/j.ijsolstr. 2014.04 .002

[22] Gardner L, Law K, Buchanan C. Unified slenderness limits for structural steel circular hollow sections. Romanian Journal of Technical Sciences, Applied Mechanics 2014;

[23] Giakoumelis G, Lam D. Axial capacity of circular concrete-filled tube columns. Journal of Constructional Steel Research 2004;60(7):1049-68. doi: $10.1016 / j \cdot j$ csr.2003.10.001

[24] Liew JYR, Xiong DX. Experimental investigation on tubular columns infilled with ultra-high strength concrete. In: Young B, editor. Proceedings of the 13th International Symposium on Tubular Structures. Hong Kong: Taylor and Francis/Balkema. ISBN 978-0-415-58473-9; 2010, p. 637-45. doi $10.1201 / \mathrm{b} 10564-88$

[25] Nseir J. Development of a new design method for the cross-section capacity of steel hollow sections. Ph.D. thesis; University of Applied Sciences of Western Switzerland Fribourg; 2015. 
[26] Ochi K, Choo B. Ultimate strength and post-buckling behaviour of CHS columns - A comparison between cold-formed and hot-finished sections. In: Coutie M, Davies G, editors. Proceedings of the Fifth International Symposium on Tubular Structures. London: E \& FN Spon; 1993, p. 16370.

[27] Starossek U, Falah N. The interaction of steel tube and concrete core in concrete-filled steel tube columns. In: Shen Z, Chen Y, Zhao X, editors. Proceedings of the 12th International Symposium on Tubular Structures. London: Taylor and Francis/Balkema; 2009, p. 75-84.

[28] Jiao H, Zhao XL. Imperfection, residual stress and yield slenderness limit of very high strength (VHS) circular steel tubes. Journal of Constructional Steel Research 2003;59(2):233-49. doi 10.1016/S0143-974X (02)00025-1.

[29] Zhao XL. Section capacity of very high strength (VHS) circular tubes under compression. Thin-Walled Structures 2000;37(3):223-40. doi:10. 1016/S0263-8231(00)00017-3.

[30] Chen W, Ross D. Tests of fabricated tubular columns. Journal of the Structural Division 1977;100(3):619-34.

[31] Elchalakani M, Zhao XL, Grzebieta R. Tests on concrete filled doubleskin (CHS outer and SHS inner) composite short columns under axial compression. Thin-Walled Structures 2002;40(5):415-41. doi 10.1016/ S0263-8231(02)00009-5.

[32] Johansson M, Gylltoft K. Mechanical behavior of circular steel-concrete composite stub columns. Journal of Structural Engineering ASCE 2002;128(8):1073-81.

[33] Kamba T. Stub column test of high-strength CHS steel column with small diameter-to-thickness ratio. In: Farkas J, Jarmai K, editors. Proceedings of the Seventh International Symposium on Tubular Structures. Rotterdam: A.A. Balkema; 1996, p. 397-404. 
[34] Ma J, Chan TM, Young B. Cold-formed high strength tubular sections of steel grade up to 1100 MPA. In: Camotim D, Chan SL, editors. Eighth International Conference on Advances in Steel Structures. Lisbon; 2015,.

[35] O'Shea M, Bridge R. Local buckling of thin-walled circular steel sections with or without internal restraint. Journal of Constructional Steel Research 1997;41(2):137-57.

[36] Prion HGL, Birkemoe PC. Beam-column behavior of fabricated steel tubular members. Journal of Structural Engineering ASCE 1992;118(5):121332. doi:10.1061/(ASCE) 0733-9445(1992) 118:5(1213)

[37] Ren QX, Han LH, Lam D, Hou C. Experiments on special-shaped CFST stub columns under axial compression. Journal of Constructional Steel Research 2014;98:123-33. doi $10.1016 / j \cdot j c s r .2014 .03 .002$.

[38] Sakino K, Nakahara H, Morino S, Nishiyama I. Behavior of centrally loaded concrete-filled steel-tube short columns. Journal of Structural Engineering ASCE 2004;130(2):180-8.

[39] Schmidt H. Thick-walled tubular members under axial compression. In: Niemi E, Makelainen P, editors. Proceedings of the 3rd International Symposium on Tubular Structures. London: Elsevier Applied Science; 1989, p. $356-63$.

[40] Teng J, Hu Y. Behaviour of FRP-jacketed circular steel tubes and cylindrical shells under axial compression. Construction and Building Materials 2007;21(4):827-38. doi $10.1016 / j$. conbuildmat.2006.06.016.

[41] Toi Y, Yuge K, Obata K. Basic studies on the crashworthiness of structural elements Part 2 Non-axisymmetric crush tests of circular cylinders and finite element analysis (in Japanese). Journal of The Society of Naval Architects of Japan 1986;161:296-305.

[42] Toi Y, Ine T. Basic studies on the crashworthiness of structural elements Part 5 Axisymmetric crush tests of circular cylinders and finite element 
analysis (in Japanese). Journal of The Society of Naval Architects of Japan 1988;164:406-19.

[43] Tutuncu I, O'Rourke T. Compression behavior of nonslender cylindrical steel members with small and large-scale geometric imperfections. Journal of Structural Engineering ASCE 2006;132(8):1234-41.

[44] Wei S, Mau ST, Vipulanandan C, Mantrala SK. Performance of a new sandwich tube under axial loading: Experiment. Journal of Structural Engineering ASCE 1995;121(12):1806-14.

[45] Xiao Y, He W, Choi Kk. Confined concrete-filled tubular columns. Journal of Structural Engineering ASCE 2005;131(3):488-97. doi 10.1061/(ASCE) 0733-9445(2005) 131:3(488)

[46] Yu T, Teng J. Hybrid FRP-concrete-steel double-skin tubular columns with a square outer tube and a circular inner tube: Stub column tests. In: Young B, editor. Proceedings of the 13th International Symposium on Tubular Structures. London: Taylor and Francis/Balkema; 2010, p. 629-36.

[47] Zhao XL, Tong LW, Wang XY. CFDST stub columns subjected to large deformation axial loading. Engineering Structures 2010;32(3):692-703. doi:10.1016/j.engstruct.2009.11.015.

[48] Burgan BA, Baddoo NR, Gilsenan KA. Structural design of stainless steel members - comparison between Eurocode 3, Part 1.4 and test re-

n sults. Journal of Constructional Steel Research 2000;54(1):51-73. doi 10. 1016/S0143-974X(99) 00055-3.

[49] Gardner L, Nethercot DA. Experiments on stainless steel hollow sections Part 1: Material and cross-sectional behaviour. Journal of Constructional Steel Research 2004;60(9):1291-318. doi 10.1016/j.jcsr.2003.11.006.

[50] Kuwamura H. Local buckling of thin-walled stainless steel members. Steel Structures 2003;3:191-201. 
[51] Lam D, Gardner L. Structural design of stainless steel concrete filled columns. Journal of Constructional Steel Research 2008;64(11):1275-82. doi $10.1016 / j \cdot j \operatorname{jsr} .2008 .04 .012$.

[52] Rasmussen K. Recent research on stainless steel tubular structures. Journal of Constructional Steel Research 2000;54(1):75-88.

[53] Rasmussen K, Hancock G. Design of cold-formed stainless steel tubular members. I: columns. Journal of Structural Engineering ASCE $1993 ; 119(8): 2349-67$.

[54] Talja A. Test report on welded I and CHS beams, columns and beamcolumns. Report to ECSC VTT Building Technology, Finland 1997;

[55] Uy B, Tao Z, Han L. Behaviour of short and slender concrete-filled stainless steel tubular columns. Journal of Constructional Steel Research 2011;67(3):360-78. doi $10.1016 / j \cdot j \operatorname{csr} .2010 .10 .004$

[56] Young B, Hartono W. Compression tests of stainless steel tubular members. Journal of Structural Engineering ASCE 2002;128(6):754-61. doi 10.1061/ (ASCE) 0733-9445(2002)128:6(754).

[57] Zhao O, Gardner L, Young B. Structural performance of stainless steel circular hollow sections under combined axial load and bending - Part 1: Experiments and numerical modelling. Thin-Walled Structures (submitted.);xx:xx.

[58] Bardi F, Kyriakides S. Plastic buckling of circular tubes under axial compression - part I: Experiments. International Journal of Mechanical Sciences 2006;48(8):830-41. doi 10.1016/j.ijmecsci.2006.03.005.

[59] Paquette JA, Kyriakides S. Plastic buckling of tubes under axial compression and internal pressure. International Journal of Mechanical Sciences 2006;48(8):855-67. doi 10.1016/j.ijmecsci.2006.03.003. 
[60] Stangenberg H. Report to the ECSC - Draft final report ferritic stainless steels. Tech. Rep.; RWTH; 2000.

[61] Zhou F, Young B. Concrete-filled aluminum circular hollow section column tests. Thin-Walled Structures 2009;47(11):1272-80. doi 10.1016/j.tws. 2009.03 .014

[62] Zhu J, Young B. Experimental investigation of aluminum alloy circular hollow section columns. Engineering Structures 2006;28(2):207-15. doi 10 . $1016 / j$.engstruct.2005.07.012.

[63] Gresnigt AM, van Foeken RJ. Local buckling of UOE and seamless steel pipes. In: Chung J, Matsui T, Moshagen H, editors. Proceedings of the Eleventh (2001) International Offshore and Polar Engineering Conference. Stavanger. ISBN 1880653516; 2001, p. 131-42.

[64] Rondal J, Boeraeve P, Sedlacek G, Langenberg P. Rotation Capacity of Hollow Beam Sections - Research project No. 2P. Tech. Rep.; CIDECT; 1995.

[65] Sedlacek G, Dahl W, Stranghöner N, Kalinowski B, Rondal J, Boeraeve P. Investigation of the rotation behaviour of hollow section beams. ECSC Research project, final report, 7210/SA/119 1995;.

[66] Sherman DR. Tests of circular steel tubes in bending. Journal of the Structural Division 1976;102(11):2181-95.

[67] Jiao H, Zhao XL. Section slenderness limits of very high strength circular 520 _ steel tubes in bending. Thin-Walled Structures 2004;42(9):1257-71. doi 10. 1016/j.tws.2004.03.020.

[68] Elchalakani M, Zhao XL, Grzebieta R. Bending tests to determine slenderness limits for cold-formed circular hollow sections. Journal of Construc1. tional Steel Research 2002;58(11):1407-30. doi 10.1016/S0143-974X (01) 00106-7. 
[69] Guo L, Yang S, Jiao H. Behavior of thin-walled circular hollow section tubes subjected to bending. Thin-Walled Structures 2013;73:281-9. doi 10.1016/ j.tws.2013.08.014.

[70] Haedir J, Bambach MR, Zhao XL, Grzebieta RH. Strength of circular hollow sections (CHS) tubular beams externally reinforced by carbon FRP sheets in pure bending. Thin-Walled Structures 2009;47(10):1136-47. doi $10.1016 /$ j.tws.2008.10.017.

[71] Jirsa JO, Lee FH, Wilhoit Jr. JC, Merwin JE. Ovaling of pipelines under pure bending. In: Proceedings of the Offshore Technology Conference. Dallas; 1972, p. 573-9.

[72] Kabir MH, Fawzia S. Durability study of CFRP strengthened steel circular hollow sections members under marine environment. In: Smith S, editor. 23rd Australasian Conference on the Mechanics of Structures and Materials (ACMSM23). December; Byron Bay, Australia; 2014, p. 1-6.

[73] Seica M, Packer J, Ramirez P, Bell SAH, Zhao X. Rehabilitation of tubular members with carbon reinforced polymers. In: Packer J, Willibald S, editors. Proceedings of the 11th International Symposium and IIW International Conference on Tubular Structures. London: Taylor and Francis/Balkema; 2006, p. 365-73.

[74] Kiymaz G. Strength and stability criteria for thin-walled stainless steel circular hollow section members under bending. Thin-Walled Structures 2005;43(10):1534-49. doi $10.1016 / j$.tws .2005.06.006.

[75] Rasmussen K, Hancock G. Design of cold-formed stainless steel tubular members. II: beams. Journal of Structural Engineering ASCE 550 1993;119(8):2368-86.

[76] Su MN, Young B, Gardner L, Buchanan C. A Review of Flexural Design for Aluminum Alloy Circular Hollow Sections. Engineering Structures (submitted.);xx:xx. 
[77] Zhu J, Young B. Aluminum alloy circular hollow section beam-columns. Thin-Walled Structures 2006;44(2):131-40. doi 10.1016/j.tws.2006.02. 006.

[78] Chan T, Gardner L. Bending strength of hot-rolled elliptical hollow sections. Journal of Constructional Steel Research 2008;64(9):971-86. doi $10.1016 / j \cdot j \operatorname{csr} .2007 .11 .001$

[79] American Iron and Steel Institute . Commentary on Appendix 1 Design of Cold-Formed Steel Structural Members with the Direct Strength Method. Tech. Rep.; 2004.

[80] Gardner L, Yun X, Macorini L, Kucukler M. The continuous strength method for hot-rolled steel and steel-concrete composite design. In: Proceedings of the Eleventh International Conference on Advances in Steel and Concrete Composite Structures (ASCCS). Tsinghua University, Beijing, China; 2015,.

[81] Rasmussen K. Full-range stress-strain curves for stainless steel alloys. Journal of Constructional Steel Research 2003;59(2003):47-61.

[82] Bock M, Gardner L, Real E. Material and local buckling response of ferritic 口 stainless steel sections. Thin-Walled Structures 2015;89:131-41. doi:10. $1016 / \mathrm{j}$.tws. 2014.12.012.

[83] Real E, Arrayago I, Mirambell E, Westeel R. Comparative study of analytical expressions for the modelling of stainless steel behaviour. Thin-Walled Structures 2014;83:2-11. doi $10.1016 /$ j.tws.2014.01.026.

[84] Arrayago I, Real E, Gardner L. Description of stress-strain curves for stainless steel alloys. Materials \& Design 2015;87:540-52. doi:10.1016/j. matdes.2015.08.001

[85] Liew A. Design of structural steel elements with the Continuous Strength Method. Ph.D. thesis; Imperial College London; 2014. 
[86] Chan T, Gardner L. Compressive resistance of hot-rolled elliptical hollow sections. Engineering Structures 2008;30(2):522-32. doi 10.1016/j. engstruct.2007.04.019. 